\title{
LOW-VELOCITY IMPACT BEHAVIOUR OF OPEN-CELL FOAMS
}

\author{
RezA Hedayati \\ Department of Mechanical Engineering, Amirkabir University of Technology (Tehran Polytechnic), Hafez Ave, \\ Tehran, Iran, and Faculty of Aerospace Engineering, Delft University of Technology, Delft, Netherlands \\ e-mail: r.hedayati@tudelft.nl; rezahedayati@gmail.com \\ Mojtaba SAdighi \\ Department of Mechanical Engineering, Amirkabir University of Technology (Tehran Polytechnic), Hafez Ave, \\ Tehran, Iran
}

\begin{abstract}
Metal foams are cellular solids that show some unique properties which cannot be found in other natural or human-made materials. While the impact characteristics of closed-cell foams under static and impact loadings appear to be well-studied in the literature, the impact behaviour of open-cell foams is not yet well-understood. In this study, open-cell foams with two different densities are impacted by drop weights with different kinetic energies. The effects of foam density, impactor initial height, and impactor weight on the recorded stresstime, stress-strain, and energy-strain curves are investigated. While the stress-strain curve of closed-cell foams under impact loading usually consists of a single bell, the results of the current study showed that both the stress-time and stress-strain curves of most the samples consist of two consecutive bells. By increasing weight of the impacting weight, the number of bells increases which helps in increasing the impact period and keeping the maximum generated stress low. Compared to closed-cell foams, the open-cell foams can therefore better absorb the energy, as long as the impact energy is relatively small. The relatively low stiffness as well as the presence of large hollow space inside the open-cell foams also makes them favorable for being used as biomedical scaffolds.
\end{abstract}

Keywords: open-cell foam, low-velocity impact, biomaterial, mechanical properties

\section{Introduction}

Metal foams are a class of cellular materials that show some unique properties which cannot be found in other natural or human-made materials. For example, their specific stiffness and energy absorption capacity are relatively high even for small specific densities (Schüler et al., 2013). Foams are usually categorized into two main groups: open-cell and closed-cell. In closed-cell foams, the cells are completely separated from each other by walls. In open-cell foams, there is no cell wall and the cells are connected to each other by cell edges.

While the energy absorption characteristics of closed-cell foams appear to be well-studied in the literature (Schüler et al., 2013; Fang et al., 2015; Wang et al., 2015; Zhang et al., 2013; Ramachandra et al., 2003; Mukai et al., 2006; Hedayati et al., 2011), the impact behaviour of open-cell foams is not yet well-understood. The main reason can be the difference in the applications that have been considered for decades for the two noted types of foams. Due to higher stiffness and plateau stress levels, closed-cell foams are usually preferred to open-cell foams in energy absorption applications. On the other hand, permeability provided by connectivity of the cells of open-cell foams makes them suitable for applications in which the fluid flow through the foam cells is important, e.g. as heat exchanger or as bone substitute implants. If open-cell foams with small cells are filled by viscous fluids, the expelling of the fluid under a compressive load can also dissipate a great amount of energy (Gibson and Ashby, 1997). 
Novel applications found for open-cell foams (such as their use as bone substitute biomaterials) has made understanding of their mechanical properties under different loading conditions important. Depending on their location and person, human bones can have a large range of stiffness from $0.1 \mathrm{GPa}$ to $20 \mathrm{GPa}$. Particularly, the inner soft and weak tissues of bones, known as cancellous or spongy bones, usually have very small stiffnesses. Solid implants usually remove the load from natural bones around them leading to their resorption. This resorption is followed by detaching the implant from the surrounding bone and, therefore, malfunction of the implant (known as stress shielding). Open-cell foams have low stiffness levels which are comparable to the stiffness levels of bones. Moreover, their hollow space allows for new bone regeneration inside the implant and, therefore, better bone-implant fixation.

Regarding the mechanical properties of open-cell foams, Kashef et al. (2008) fabricated opencell titanium foams using space holder technique and investigated their elastic properties, fracture toughness (Kashef et al., 2010) and fatigue strength (Kashef et al., 2011) for biomedical applications. They found $63 \%$ porous foams with $6.5 \mathrm{GPa}$ elastic modulus suitable for dental and orthopaedic applications (Kashef et al., 2008). The elastic mechanical properties of opencell foams fabricated by directional solidification (Nich et al., 2000), casting (Yamada et al., 2000; Kanahashi et al., 2000) and space-holder (Jianget al., 2007) techniques have also been investigated in the literature. The effect of the strain rate on the dynamic mechanical properties of different types of open-cell foams have also been studied in several publications (Yi et al., 2001; Wang et al., 2006). However, the mechanical behaviour of open-cell foams under the impact of drop weights has not yet been studied.

Similar to bulk pure copper, copper foams have great corrosion resistance, and they possess excellent electrical and thermal conductivities. Copper foams are excellent candidates for energy absorption applications as well. This is because the possibility of having a large proportion of hollow space inside the open-cell porous structures allows for large plastic deformation of struts (and therefore high energy absorption capacity of the porous structure) until the neighbour struts come into contact with each other. The great ductility properties of copper (compared to other metals) even increases this great toughness capability observed in metal foams.

In this study, open-cell foams with two different densities are impacted by drop weights with different kinetic energies. The effect of foam density and impactor initial energy on the recorded stress-time, stress-strain and energy-strain curves will be investigated. The effect of mass of the drop weight is the other parameter which will be studied.

\section{Materials and methods}

The open-cell copper foam samples were made by the investment casting process. Two large foam panels (Fig. 1a) were made, which were then cut into several small cubic specimens (Fig. 1b) with dimensions of $22.6 \mathrm{~mm} \times 28.2 \mathrm{~mm} \times 39.2 \mathrm{~mm}$. The foam samples had two nominal densities of $268.03 \mathrm{~kg} / \mathrm{m}^{3}$ and $393.596 \mathrm{~kg} / \mathrm{m}^{3}$ (Table 1), respectively named low-density (LD) and high-density (HD) foams in this study. The specimens cut from the edges of the foam panel were not used in order to avoid non-homogeneity in the micro-structure of the foam. To measure density of the foam samples, the weight and dimensions of all the samples were measured and divided. For having the relative density of the foam samples, the density of the foam samples was divided by the density of the bulk material (i.e. $8960 \mathrm{~kg} / \mathrm{m}^{3}$ ). The samples were impacted by drop weights with initial heights between $20 \mathrm{~cm}$ and $100 \mathrm{~cm}$. Two drop weights of $1.3 \mathrm{~kg}$ and $3.3 \mathrm{~kg}$ were considered. The acceleration of the impactor was recorded by an accelerometer installed on it. By two consecutive integration of the acceleration-time diagrams, displacement-time diagrams were also obtained. The force-time diagram was obtained by multiplying the vertical coordinate of the acceleration-time diagram by the mass of the impactor. The specific energy-time diagrams were 
measured by calculating the area under the stress-strain curve diagrams. The noises observed in the acceleration diagrams were smoothed using SMOOTH function in MATLAB (Fig. 3).

(a)

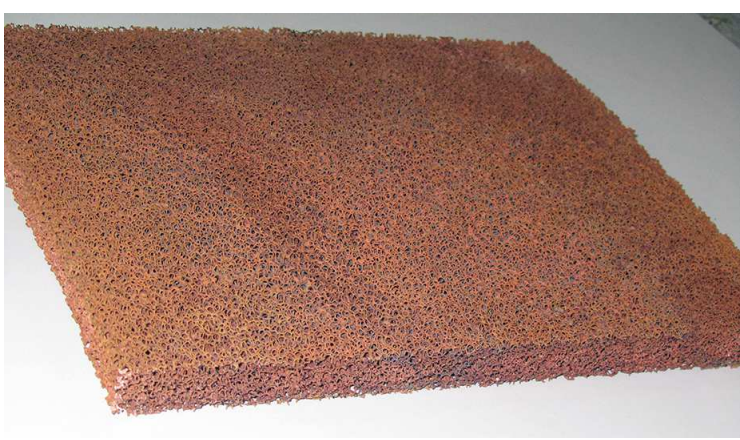

(b)

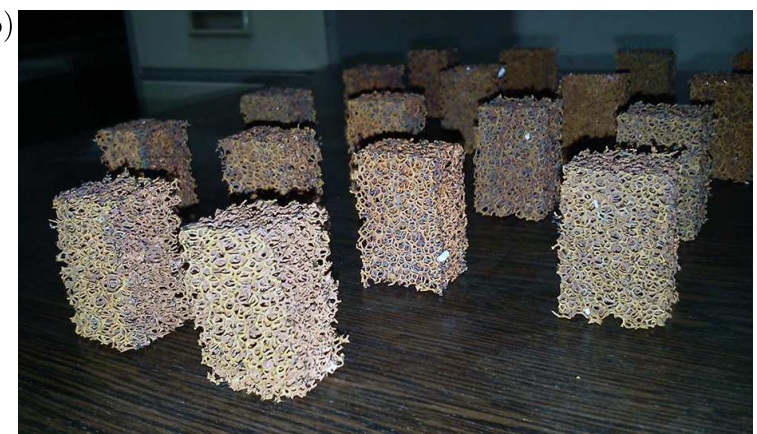

Fig. 1. (a) Foam panel before being cut, (b) samples cut from the foam panel

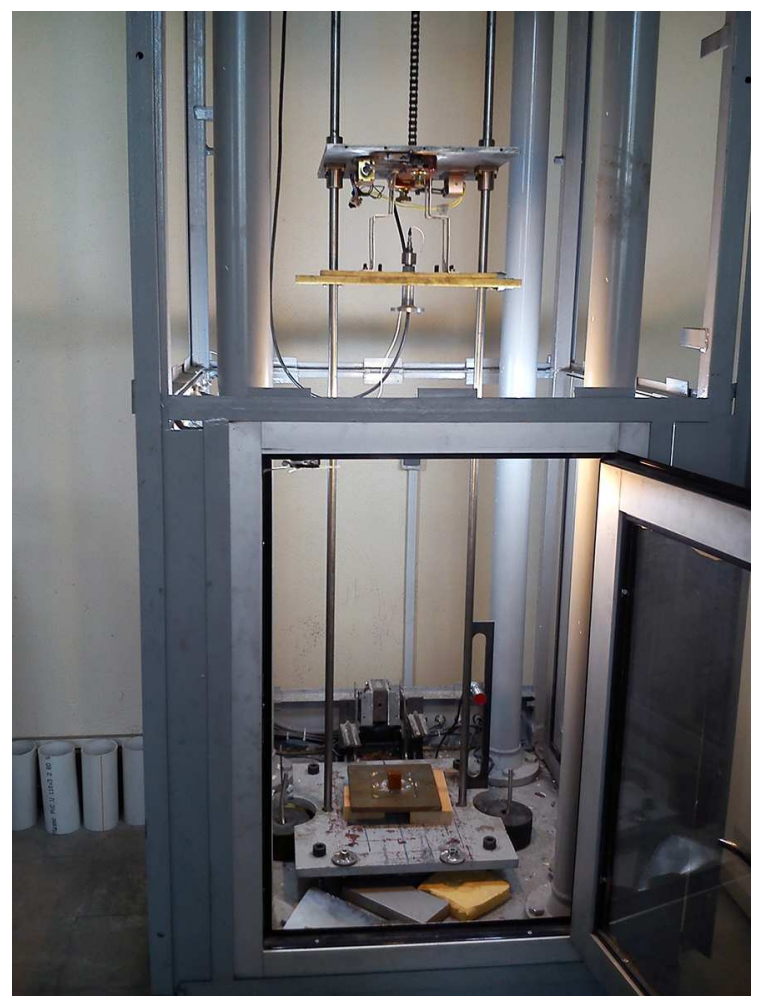

Fig. 2. A copper foam samples in the drop weight testing machine

Table 1. Geometrical properties of low-density and high-density foams

\begin{tabular}{|l|c|c|c|}
\hline & $\begin{array}{c}\text { Density } \\
\rho\left[\mathrm{kg} / \mathrm{m}^{3}\right]\end{array}$ & $\begin{array}{c}\text { Relative density } \\
\rho / \rho_{s}[\%]\end{array}$ & $\begin{array}{c}\text { Pore size } \\
a[\mathrm{~mm}]\end{array}$ \\
\hline \hline Low-density (LD) & $268.03 \pm 16.19$ & $2.99 \pm 0.169$ & $2.1<a<4.41$ \\
\hline High-density (HD) & $393.596 \pm 12.82$ & $4.391 \pm 0.143$ & $1.92<a<4.22$ \\
\hline
\end{tabular}



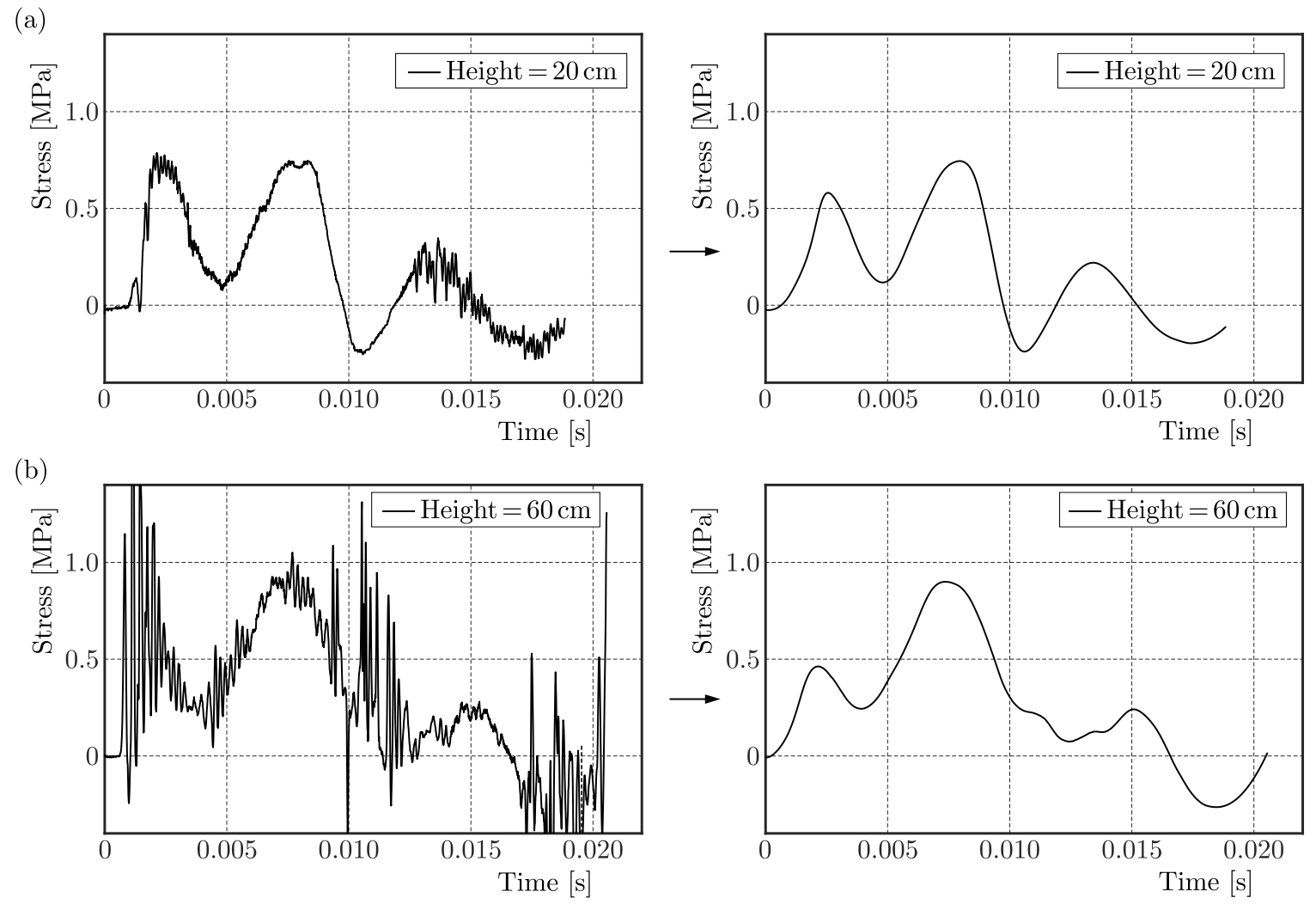

Fig. 3. Smoothing of experimental data curves for two examples of stress-time diagrams

\section{Results}

The elastic modulus of the high-density foam was almost 1.5 times of that in the low-density foam (Table 2). Both the yield stress and plateau stress of the high-density foam were almost twice of those for the low-density foam (Table 2). Both types of foams demonstrated close densification strains around 0.8 (Fig. 4). The stress-strain curves of both the foams coincided at the strain of 0.9 (Fig. 4).

Table 2. Mechanical properties of low-density and high-density foams

\begin{tabular}{|c|c|c|c|c|}
\hline & $\begin{array}{c}\text { Elastic modulus } \\
E[\mathrm{MPa}]\end{array}$ & $\begin{array}{c}\text { Relative elastic modulus } \\
E / E_{s} \cdot 10^{-4}\end{array}$ & $\begin{array}{c}\text { Yield stress } \\
\sigma_{y}[\mathrm{kPa}]\end{array}$ & $\begin{array}{c}\text { Plateau stress } \\
\sigma_{p l}[\mathrm{kPa}]\end{array}$ \\
\hline \hline LD & $20.333 \pm 3.78$ & $1.7378 \pm 0.323$ & $651.1 \pm 131.4$ & $605.47 \pm 185.9$ \\
\hline HD & $30.034 \pm 5.919$ & $2.5669 \pm 0.506$ & $1316.2 \pm 198.6$ & $1512.1 \pm 336.7$ \\
\hline
\end{tabular}

Due to limitations in the recording period of the accelerometer, the stress of all the samples under the impact loading could be captured up to $20 \mathrm{~ms}$. Both the low-density and high-density foams showed double bell curves in their stress-time diagrams (Fig. 5). In general, increasing the initial height of the impacting weight increased the maximum stress values of both the first and second bells (Fig. 5). There were, however, some exceptions. For example, the maximum stress of the first bell of the test with the initial height of $h=20 \mathrm{~cm}$ was even larger than that in other tests. The end times of the second bell for low-density foams with different initial heights of the impacting weights were between $10 \mathrm{~ms}$ and $14 \mathrm{~ms}$. The end-times of the second bell of all the high-density foams were close and were between $8 \mathrm{~ms}$ and $9 \mathrm{~ms}$.

While in low-density foams, the maximum stress of the first bell was always lower than that of the second bell, in high-density foams, the maximum stress of the first and second bells 


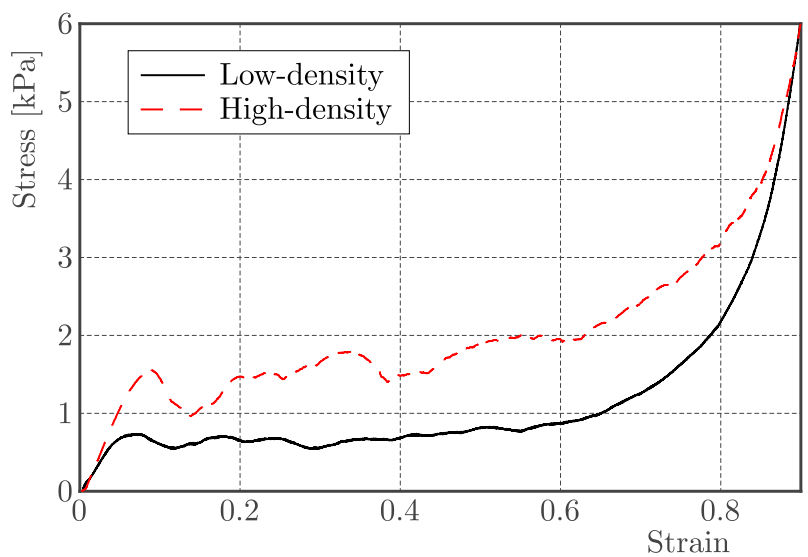

Fig. 4. Stress-strain curve of low-density and high-density foams under quasi-static loading
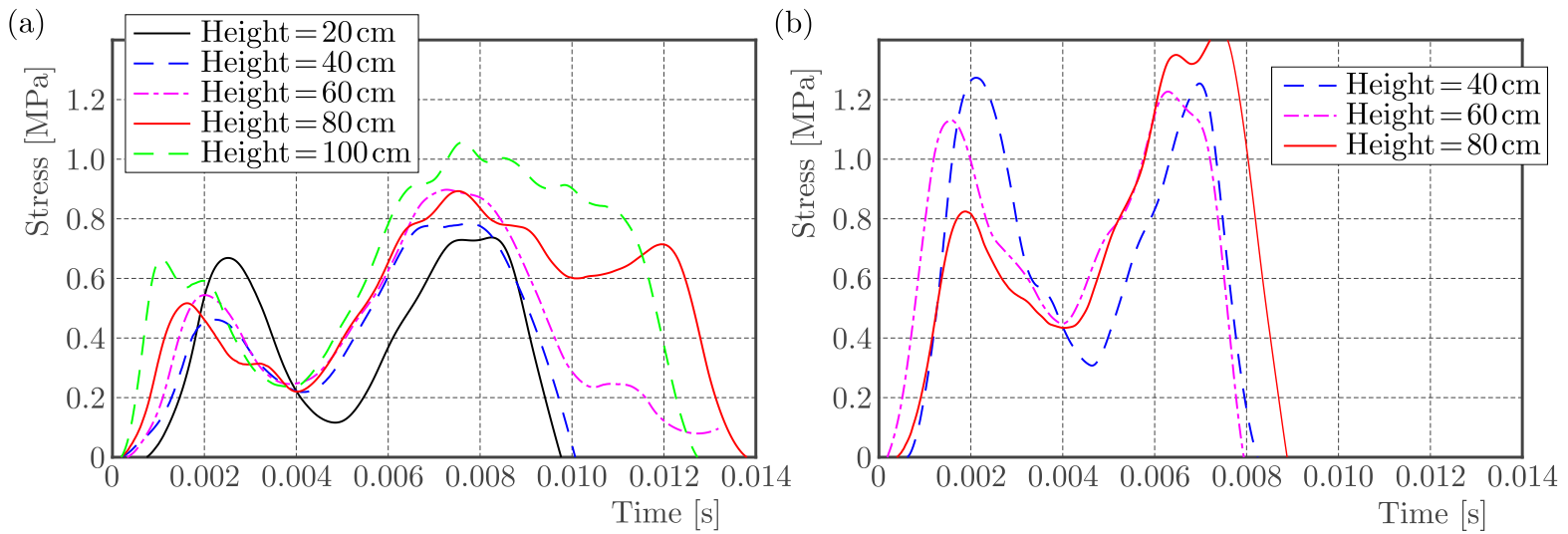

Fig. 5. Stress-time curves of (a) low-density and (b) high-density foams impacted by an impactor with $1.3 \mathrm{~kg}$ weight

were close to each other (Fig. 5). As expected, for the same initial height of the impactor, the maximum stress generated in the low-density foam samples were always lower than that in the high-density foam (Fig. 5).

(a)

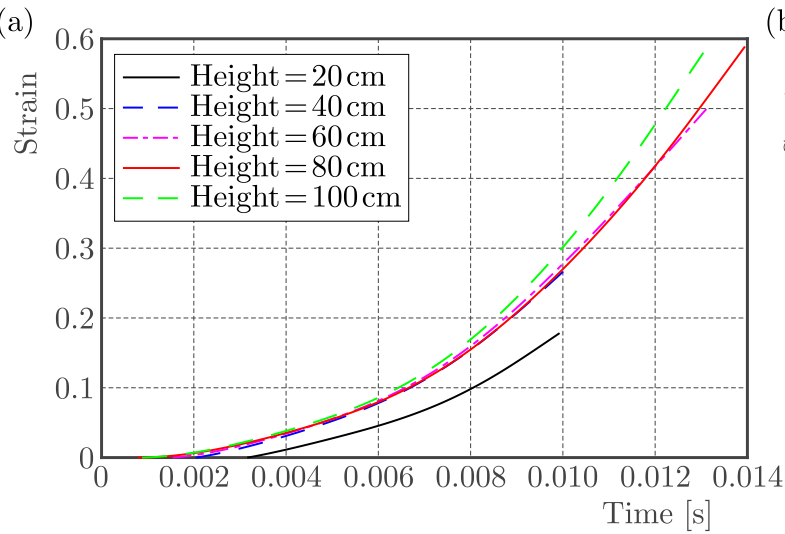

(b)

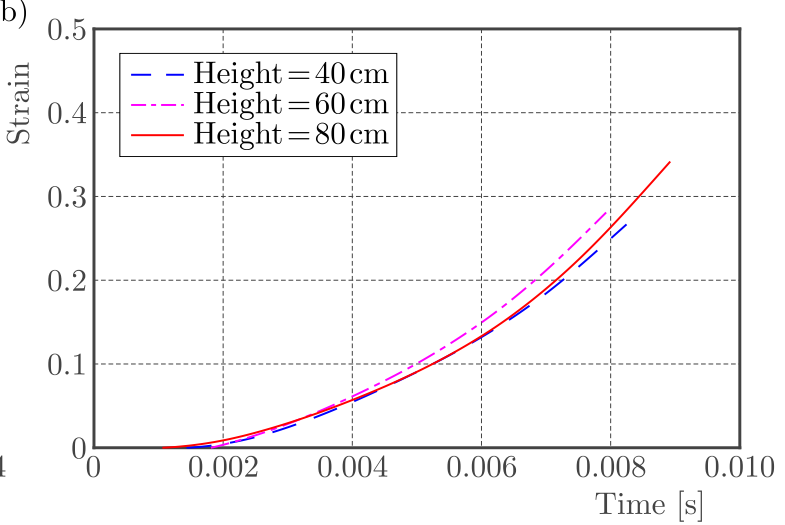

Fig. 6. Strain-time curves of (a) low-density and (b) high-density foams impacted by an impactor with $1.3 \mathrm{~kg}$ weight

As expected, increasing the initial height increased the final strain (maximum compaction) of the foam samples (Fig. 6). In low-density samples, the maximum strain in the samples for initial heights of $20 \mathrm{~cm}, 40 \mathrm{~cm}, 60 \mathrm{~cm}, 80 \mathrm{~cm}$, and $100 \mathrm{~cm}$ was respectively $18.5 \%, 28.5 \%, 50 \%$, $58.8 \%$, and $56 \%$ (Fig. 6a). In high-density samples, the maximum strains for initial heights of 
$40 \mathrm{~cm}, 60 \mathrm{~cm}$, and $80 \mathrm{~cm}$ were respectively $26.6 \%, 28.1 \%$, and $34.2 \%$ (Fig. 6b). As expected, for the same initial height of the impacting weight, the maximum strains of the high-density samples were always lower than those in the low-density samples (compare Fig. 6a and Fig. 6b). While in the stress-time curves (Fig. 5), the span of the second bell was very close to the span of the first bell, in the stress-strain curves (Fig. 7), the span of the first bell was much smaller than the span of the second bell, especially for the low-density foams.
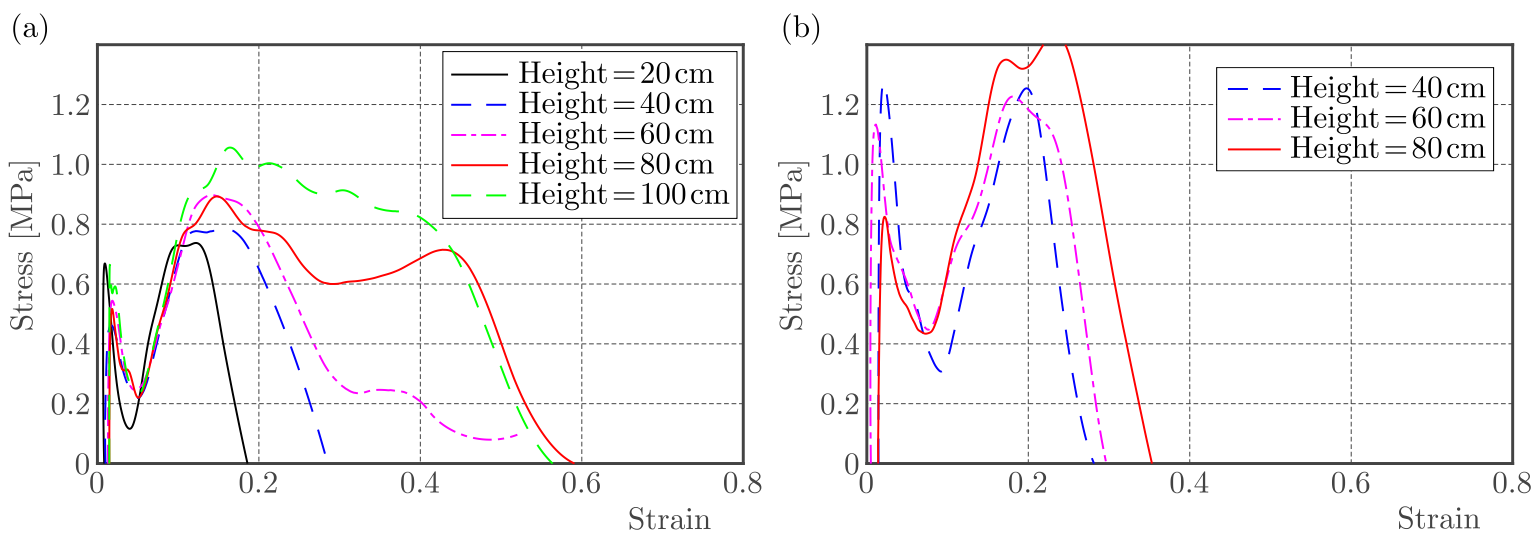

Fig. 7. Stress-strain curves of (a) low-density and (b) high-density foams impacted by an impactor with $1.3 \mathrm{~kg}$ weight
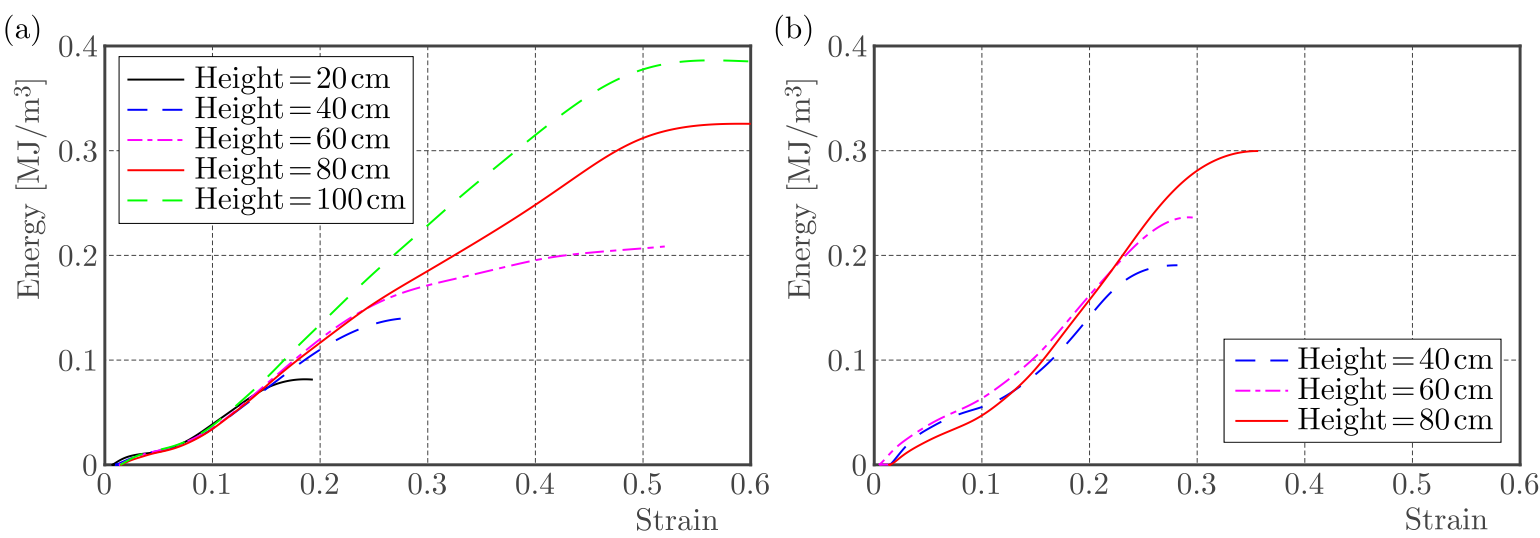

Fig. 8. Absorbed specific energy profiles of (a) low-density and (b) high-density foams impacted by an impactor with $1.3 \mathrm{~kg}$ weight

Increasing the initial height of the impactor increased the final energy absorbed by both the low-density and high-density foams (Fig. 8). Plotting the normalized values of the absorbed energy (i.e. the ratio of the absorbed energy by the sample to the initial energy of the impactor) showed that the final absorbed energy in all the foam samples were between $70 \%$ and $92 \%$ of the initial energy of the impactor (Fig. 9). The highest percentage of the final absorbed energy (about $92 \%$ ) belonged to the high-density foam under the impact of the weight with the lowest initial height, i.e. $40 \mathrm{~cm}$ (Fig. 9b). The normalized energy-strain diagrams of the low-density foams with the impactor initial heights of $80 \mathrm{~cm}$ and $100 \mathrm{~cm}$ were very close (Fig. 9a).

The effect of impactor weight was investigated on the low-density foam under the impact of weight with the initial height of $40 \mathrm{~cm}$. Increasing the weight of the impactor did not have a significant effect on the maximum stress of the first bell (Fig. 10). Moreover, increasing the impactor weight did not significantly change the time and strain of the maximum stress of the first bell. However, increasing the impactor weight increased the maximum stress of the second bell and decreased its occurrence time (Fig. 10a). More significantly, the stress value of the 
sample under the impact of the heavy impactor did not reach zero after the second bell, and a third bell was formed in both the stress-time and stress-strain diagrams (Fig. 10).
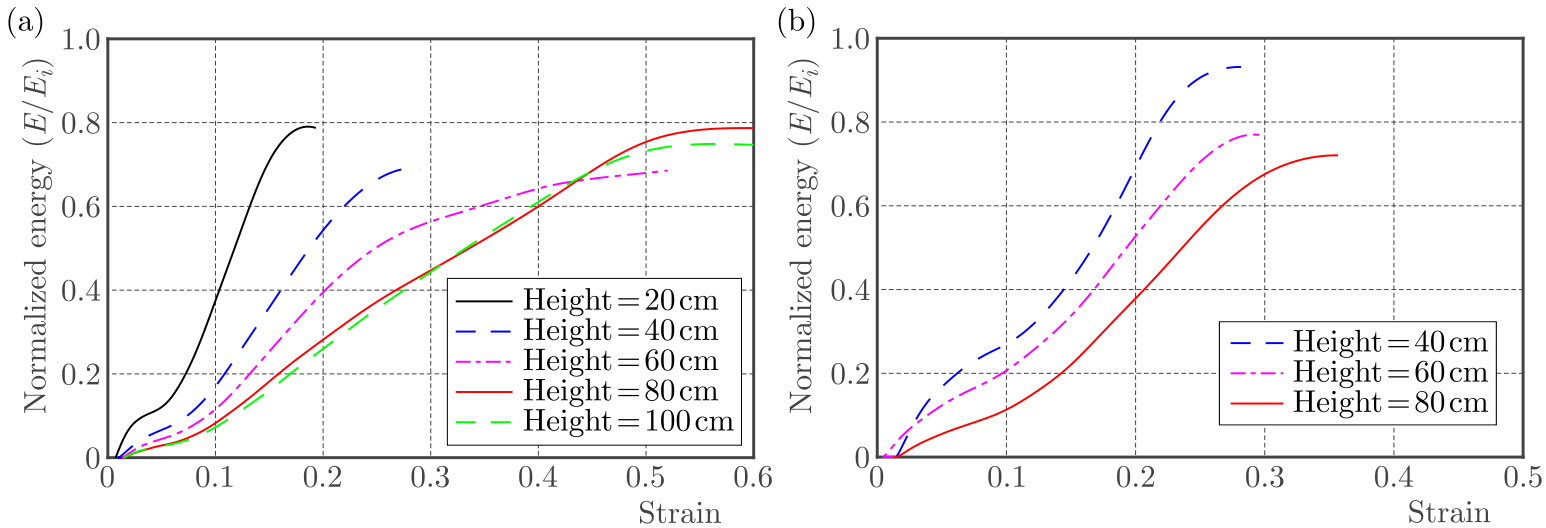

Fig. 9. Normalized absorbed energy profiles of (a) low-density and (b) high-density foams impacted by an impactor with $1.3 \mathrm{~kg}$ weight
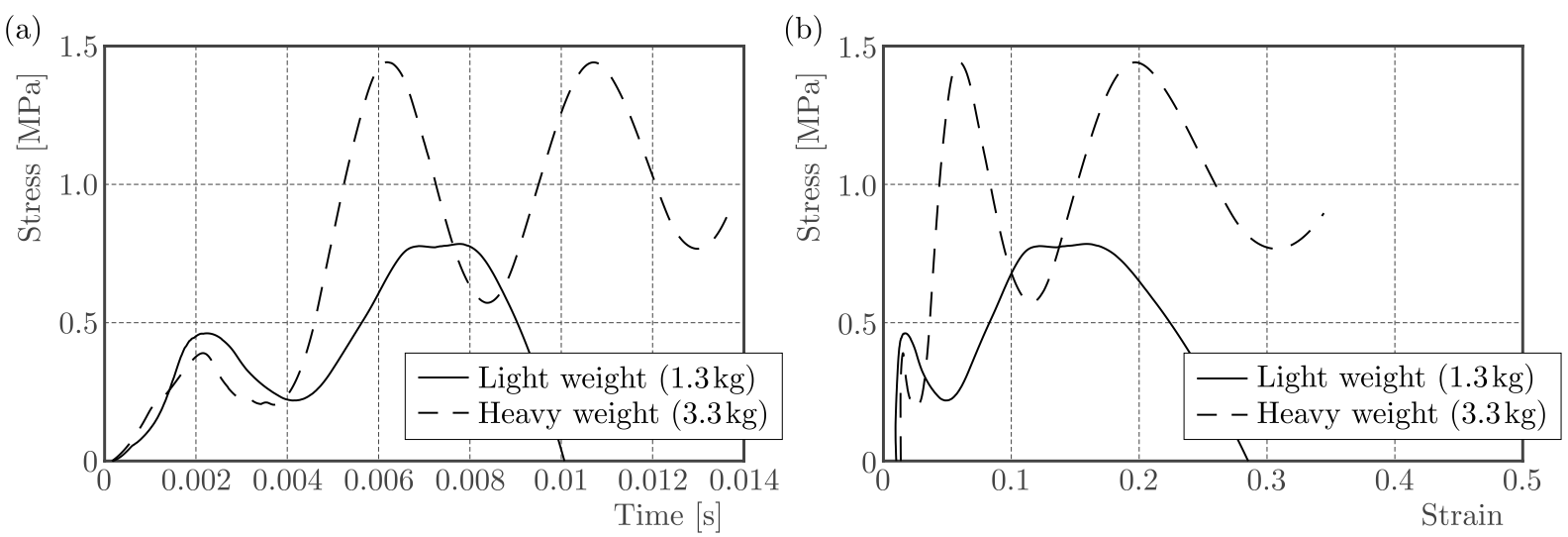

Fig. 10. (a) Stress-time and (b) stress-strain curves of low-density foams under the impact of $1.3 \mathrm{~kg}$ and $3.3 \mathrm{~kg}$ impactors

\section{Discussions}

All the stress-time and stress-strain curves consisted of a double bell. Similar bells have also been observed in other experimental and numerical studies on the impact behaviour of closedcell foams. In some cases, the stress-time curve only consisted of a single bell (Rajendran et al., 2009), while in some cases there was a double bell in the curves, although the span of the first bell was usually very tiny compared to the span of the second bell (Li et al., 2012; Castro et al., 2013; Peroni et al., 2013). The presence of the first bell in the curves can be due to reduction in the stress level in the top face of the specimen after the initial increase in the stress level after the occurrence of the impact.

In the open-cell foams, due to slow propagation of stress waves, the upper part of the specimen initially deforms very easily before the compressive wave is returned from the back plate. Due to fast initial deformation of the upper part of the open-cell foam, the elevated stress level in the interface between the foam sample and the impacting weight decreases fast. After the compressive stress waves have travelled towards and back from the lower parts of the foam and after causing deformation in the foam, the stress level decreases. However, as the impactor moves forward, the stress level increases for a second time. 
In the closed-cell foams, the cells are connected to each other by means of cell walls, while in the open-cell foams, the struts connect the cells. In the closed-cell foams, therefore, the initial stress waves can travel to the lower parts of the specimen much faster as compared to the open-cell foams. The deformation of the closed-cell foams can therefore be distributed more uniformly throughout its length. This explains the absence or very little presence of the first bell in the stress-time and stress-strain curves of the closed-cell foams.

The non-uniform deformation of the open-cell foams can increase the impact duration as compared to the closed-cell foams. This increase in the impact duration as well as the weaker nature of open-cell foams decreases the maximum stress in the foam during the impact. Therefore, as compared to the closed-cell foams, the open-cell foams, if used as energy absorbing materials in packaging industry, can better protect delicate goods, since the stress imposed on the package is much lower, as long as the impact energy is relatively small.

After the initial double bell curves, the stress-time curves of the open-cell foams continued in a sine wave shape around zero stress. In all the samples, the accumulation of strain after the second bell was very small, which showed that the sine wave shape of the stress-time curve after the second bell had been caused by vibration of the test machine and specimen rather than the actual displacement of the interface between the specimen and the impacting weight. Therefore, the periodic sine waves after the second bell (in the impacts with light impactor) were omitted from the curves.

The stress value of the sample under the heavy impactor $(3.3 \mathrm{~kg})$ did not reach zero after the second bell, and a third bell was formed in both the stress-time and stress-strain diagrams (Fig. 10). Due to limitations in measurement duration, the acceleration could not be measured after the third bell. However, the reason behind the formation of additional bells in the stress-strain curve can be the fact that when the weight of the impactor is increased, the layer-by-layer nature of the deformation of the foam sample increases. This is because in the case of heavier impactors, the foam sample is not tough enough to decrease velocity of the impactor down to zero after the second bell, leading to creation of additional bells in the curves.

After being deformed, none of the samples could absorb all the initial energy of the impacting weight (Fig. 9). The reason behind this can be the dissipation of energy caused by friction between the sample and the impacting weight, friction of the impacting weight with the guiding rail of the testing machine, and conversion of mechanical energy to heat due to plastic deformation during the impact. However, plotting the normalized values of absorbed energy demonstrated that the final absorbed energy in all the foam samples are between $70 \%$ and $92 \%$ of the initial energy of the impactor, which shows that high percentages of initial energy have been absorbed by the foam samples.

Using open-cell foams for production of bone-replacing implants is becoming more and more common. The open-cell foams manufactured using the traditional methods usually have an irregular morphology. The manufacturing processes that create relatively regular open-cell foams usually lead to a foam unit cell shape believed to have a geometry similar to the ones suggested by Kelvin (Warren and Kraynik, 1997) or Weaire and Phelan (1994). The advent of additive manufacturing techniques has made it possible to create open-cell structures with arbitrary unit cell shape and size. For example, porous open-cell foams with hexagonal (Hedayati et al., 2016c), octagonal (Hedayati et al., 2016b), truncated cube (Hedayati et al., 2018), diamond (Ahmadi et al., 2014; (Hedayati et al., 2017), truncated cuboctahedron (Doig et al., 1999), rhombic dodecahedron (Shulmeister et al., 1998; Babaee et al., 2012; Borleffs, 2012; Amin Yavari et al., 2013; Campoli et al., 2013), tetrakaidecahedrons (Warren and Kraynik, 1997; Zheng et al., 2014) and rhombicuboctahedron (Hedayati et al., 2016a) have been investigated numerically, analytically and experimentally. While additive manufacturing techniques provide good control over the micro-architecture of the porous structure, they result in porous structures with some defects. For example, the additively manufactured porous structures have irregularities in the 
strut cross-section diameter. The consecutive fusing of metal powders at neighbour points usually creates very rough surfaces with potentially high stress concentration factors. Moreover, at some points, the strut radius can be very small, which can lead to clustered damage areas. Therefore, the metal foams made by traditional manufacturing techniques still have their advantages over the newly popular additively manufactured porous structures.

\section{Conclusions}

In this paper, copper open-cell foams with two densities were tested mechanically under static and impact loadings. For the impact loading, two drop-weights with $1.3 \mathrm{~kg}$ and $3.3 \mathrm{~kg}$ masses were used. The results showed that both the stress-time and stress-strain curves of all the samples consist of two consecutive bells. While in the stress-time curves, the span of the second bell was very close to the span of the first bell, in stress-strain curves, the span of the first bell was much smaller than the span of the second bell, especially in low-density foams. As expected, for the same initial height of the impactor, the maximum stress generated in the lowdensity foam samples were always lower than that in the high-density foams. The foam samples absorbed between $70 \%$ and $92 \%$ of the initial energy of the impactor. Increasing the weight of the impactor did not have a significant effect on the maximum stress of the first bell in the stress-time diagram. Moreover, increasing the impactor weight did not change the time of the first maximum stress. However, increasing the impactor weight increased the maximum stress of the second bell and decreased its occurrence time. It can be concluded that as compared to the closed-cell foams, the open-cell foams can better absorb the energy, as long as the impact energy is relatively small. The very small stiffness as well as the presence of large interconnected space inside the open-cell foams also makes them favorable for being used as biomedical scaffolds.

\section{References}

1. Ahmadi S., Campoli G., Amin Yavari S., Sajadi B., Wauthlé R., Schrooten J., Weinans H., ZAdPoor A.A., 2014, Mechanical behavior of regular open-cell porous biomaterials made of diamond lattice unit cells, Journal of the Mechanical Behavior of Biomedical Materials, 34, 106-115

2. Amin Yavari S., Wauthlé R., van der Stok J., Riemslag A., Janssen M., Mulier M., Kruth J.-P., Schrooten J., Weinans H., Zadpoor A.A., 2013, Fatigue behavior of porous biomaterials manufactured using selective laser melting, Materials Science and Engineering: $C, \mathbf{3 3}$, $8,4849-4858$

3. Babaee S., Jahromi B.H., Ajdari A., Nayeb-Hashemi H., Vaziri A., 2012, Mechanical properties of open-cell rhombic dodecahedron cellular structures, Acta Materialia, 60, 6, 2873$-2885$

4. Borleffs M., 2012, Finite Element Modeling to Predict Bulk Mechanical Properties of 3D Printed Metal Foams, Delft University of Technology

5. Campoli G., Borleffs M., Amin Yavari S., Wauthle R., Weinans H., Zadpoor A.A., 2013, Mechanical properties of open-cell metallic biomaterials manufactured using additive manufacturing, Materials and Design, 49, 957-965

6. Castro G., Nutt S., Wenchen X., 2013, Compression and low-velocity impact behavior of aluminum syntactic foam, Materials Science and Engineering: A, 578, 222-229

7. Doig S., Boam A., Livingston A., Stuckey D., 1999, Mass transfer of hydrophobic solutes in solvent swollen silicone rubber membranes, Journal of Membrane Science, 154, 1, 127-140

8. FAng Q., Zhang J., Zhang Y., Liu J., Gong Z., 2015, Mesoscopic investigation of closed-cell aluminum foams on energy absorption capability under impact, Composite Structures, 124, 409-420 
9. Gibson L.J., Ashby M.F., 1997, Cellular Solids: Structure and Properties, Cambridge University Press

10. Hedayati R., Ahmadi S., Lietaert K., Pouran B., Li Y., Weinans H., Rans C., Zadpoor A., 2018, Isolated and modulated effects of topology and material type on the mechanical properties of additively manufactured porous biomaterials, Journal of the Mechanical Behavior of Biomedical Materials, 79

11. Hedayati R., Leeflang A., Zadpoor A., 2017, Additively manufactured metallic pentamode meta-materials, Applied Physics Letters, 110, 9, 091905

12. Hedayati R., Sadighi M., Mohammadi-Aghdam M., Zadpoor A.A., 2016a, Mechanics of additively manufactured porous biomaterials based on the rhombicuboctahedron unit cell, Journal of the Mechanical Behavior of Biomedical Materials, 53, 272-294

13. Hedayati R., Sadighi M., Mohammadi-Aghdam M., Zadpoor A.A., 2016b, Mechanical properties of additively manufactured octagonal honeycombs, Materials Science and Engineering: C, 69, 1307-1317

14. Hedayati R., Sadighi M., Mohammadi-Aghdam M., Zadpoor A.A., 2016c, Mechanical properties of additively manufactured thick honeycombs, Materials, 9, 8, 613

15. Hedayati R., Ziaei-Rad S., 2011, Foam-core effect on the integrity of tailplane leading edge during bird-strike event, Journal of Aircraft, 48, 6, 2080-2089

16. JiAng B., WANG Z., ZhaO N., 2007, Effect of pore size and relative density on the mechanical properties of open cell aluminum foams, Scripta Materialia, 56, 2, 169-172

17. Kanahashi H., Mukai T., Yamada Y., Shimojima K., Mabuchi M., Nieh T., Higashi K., 2000, Dynamic compression of an ultra-low density aluminum foam, Materials Science and Engineering: A, 280, 2, 349-353

18. Kashef S., Lin J., Hodgson P.D., YAn W., 2008, Mechanical properties of titanium foam for biomedical applications, International Journal of Modern Physics B, 22, 31-32, 6155-6160

19. Kashef S., Asgari A., Hilditch T.B., Yan W., Goel V.K., Hodgson P.D., 2010, Fracture toughness of titanium foams for medical applications, Materials Science and Engineering: A, 527, $29,7689-7693$

20. Kashef S., Asgari A., Hilditch T.B., Yan W., Goel V.K., Hodgson P.D., 2011, Fatigue crack growth behavior of titanium foams for medical applications, Materials Science and Engineering: $A, \mathbf{5 2 8}, 3,1602-1607$

21. Li B., ZhAo G., Lu T., 2012, Low strain rate compressive behavior of high porosity closed-cell aluminum foams, Science China Technological Sciences, 55, 2, 451-463

22. Mukai T., Miyoshi T., Nakano S., Somekawa H., Higashi K., 2006, Compressive response of a closed-cell aluminum foam at high strain rate, Scripta Materialia, 54, 4, 533-537

23. Nieh T., Higashi K., Wadsworth J., 2000, Effect of cell morphology on the compressive properties of open-cell aluminum foams, Materials Science and Engineering: A, 283, 1, 105-110

24. Peroni M., Solomos G., Pizzinato V., 2013, Impact behaviour testing of aluminium foam, International Journal of Impact Engineering, 53, 74-83

25. Rajendran R., Moorthi A., Basu S., 2009, Numerical simulation of drop weight impact behaviour of closed cell aluminium foam, Materials and Design, 30, 8, 2823-2830

26. Ramachandra S., Kumar P.S., Ramamurty U., 2003, Impact energy absorption in an Al foam at low velocities, Scripta Materialia, 49, 8, 741-745

27. Schüler P., Fischer S.F., Bührig-Polaczek A., Fleck C., 2013, Deformation and failure behaviour of open cell Al foams under quasistatic and impact loading, Materials Science and Engineering: A, 587, 250-261 
28. Shulmeister V., van der Burg M., van der Giessen E., Marissen R., 1998, A numerical study of large deformations of low-density elastomeric open-cell foams, Mechanics of Materials, 30, $2,125-140$

29. Wang P., Xu S., Li Z., Yang J., Zhang C., Zheng H., Hu S., 2015, Experimental investigation on the strain-rate effect and inertia effect of closed-cell aluminum foam subjected to dynamic loading, Materials Science and Engineering: A, 620, 253-261

30. WAng Z., MA H., ZhaO L., YANG G., 2006, Studies on the dynamic compressive properties of open-cell aluminum alloy foams, Scripta Materialia, 54, 1, 83-87

31. Warren W., Kraynik A., 1997, Linear elastic behavior of a low-density Kelvin foam with open cells, Journal of Applied Mechanics, 64, 4, 787-794

32. Weaire D., Phelan R., 1994, A counter-example to Kelvin's conjecture on minimal surfaces, Philosophical Magazine Letters, 69, 2, 107-110

33. Yamada Y., Shimojima K., Sakaguchi Y., Mabuchi M., Nakamura M., Asahina T., Mukai T., Kanahashi H., Higashi K., 2000, Effects of heat treatment on compressive properties of AZ91 Mg and SG91A Al foams with open-cell structure, Materials Science and Engineering: A, 280, 1, 225-228

34. Yi F., Zhu Z., Zu F., Hu S., Yi P., 2001, Strain rate effects on the compressive property and the energy-absorbing capacity of aluminum alloy foams, Materials Characterization, 47, 5, 417-422

35. Zhang Y., Sun G., Xu X., Li G., Huang X., Shen J., Li Q., 2013, Identification of material parameters for aluminum foam at high strain rate, Computational Materials Science, 74, 65-74

36. Zheng X., Lee H., Weisgraber T.H., Shusteff M., DeOtte J., Duoss E.B., Kuntz J.D., Biener M.M., GE Q., JACKson J.A., 2014, Ultralight, ultrastiff mechanical metamaterials, Science, 344, 6190, 1373-1377

Manuscript received February 7, 2017; accepted for print February 2, 2018 